\title{
Characterization of $\beta$-Estradiol 3-Glucuronidation in Rat Brain
}

\author{
Yuki Asai, Yukiko Sakakibara, Haruka Onouchi, Masayuki Nadai, and Miki Katoh* \\ Department of Pharmaceutics, Faculty of Pharmacy, Meijo University; 150 Yagotoyama, Tempaku-ku, Nagoya 468- \\ 8503, Japan. \\ Received January 27, 2017; accepted May 10, 2017
}

\begin{abstract}
$\beta$-Estradiol is conjugated by uridine 5 -diphosphate-glucuronosyltransferase (UGT) 1 A to 3-glucuronide in the human liver. UGT1A has been found in the brain; therefore, UGT1A may be involved in $\beta$-estradiol 3 -glucuronidation in the brain. In the present study, we aimed to characterize the $\beta$-estradiol 3-glucuronidation reaction in the rat brain. $\beta$-Estradiol 3-glucuronidation was detected in eight rat brain regions (cerebellum, frontal cortex, parietal cortex, piriform cortex, hippocampus, medulla oblongata, striatum, and thalamus). $\beta$-Estradiol 3-glucuronidation in the cerebellum was fitted to the Hill equation $\left(S_{50}=8.0 \mu \mathrm{M}, n=1.1\right)$. In inhibition experiments, $\beta$-estradiol 3-glucuronidation was inhibited to $73.6 \%$ in the cerebellum by $50 \mu \mathrm{M}$ bilirubin, whereas it was reduced to $20.5 \%$ with $5 \mu \mathrm{m}$ bilirubin in the liver. Unlike in the liver, Ugt1a1 may not be the main isoform catalyzing this glucuronidation in the brain. Serotonin and acetaminophen at $10 \mathrm{~mm}$ inhibited glucuronidation to 1.17 and $25.5 \%$, respectively, in the cerebellum. In induction experiments, the administration of $\beta$-naphthoflavone, carbamazepine, and phenobarbital did not increase $\beta$-estradiol 3-glucuronidation in the brain except for phenobarbital in the striatum. In addition, $\beta$-estradiol 3-glucuronidation was not correlated with serotonin or acetaminophen glucuronidation in the brain, suggesting that Ugt1a6 and Ugt1a7 are not major isoforms of $\beta$-estradiol 3-glucuronidation in the rat brain. In the present study, although we were unable to identify the isoform responsible for $\beta$-estradiol 3 -glucuronidation, we confirmed that $\beta$-estradiol could be metabolized to glucuronide in the brain under a different metabolic profile from that in the liver.
\end{abstract}

Key words $\beta$-estradiol; uridine 5 '-diphosphate-glucuronosyltransferase; brain; enzyme kinetics; inhibition; induction

Uridine 5'-diphosphate-glucuronosyltransferase (UGT) is a phase II drug-metabolizing enzyme that catalyzes the conjugation of many endogenous compounds such as neurosteroids ${ }^{1)}$ and neurotransmitters. ${ }^{2,3)}$ While UGT1A is expressed mainly in the liver, ${ }^{4}$ it is also found in extrahepatic tissues including the small intestine ${ }^{5)}$ and kidney. ${ }^{6}$ ) Recent reports showed that constitutive expression of UGT1A mRNA was detected in the brain ${ }^{7,8)}$ neurons, ${ }^{9)}$ astrocytes, ${ }^{10)}$ and microglia, ${ }^{11)}$ implying that UGT1A may be involved in modulating the concentrations of neurosteroids and neurotransmitters in the central nervous system.

A female sex steroid, $\beta$-estradiol is synthesized by aromatase from testosterone in the ovary or testis ${ }^{12}$ and is also produced in the brain. ${ }^{13)} \beta$-Estradiol has a protective effect in neuronal cells against oxidative stress during ischemic brain injury $^{14)}$ and Alzheimer's disease. ${ }^{15)}$ The major metabolic pathway of $\beta$-estradiol involves glucuronidation at 3-hydroxy position. ${ }^{16)} \beta$-Estradiol 3 -glucuronide is formed by UGT1A1, UGT1A3, UGT1A8, UGT1A10, UGT2A1, and UGT2A2 in humans. ${ }^{17)}$ Considering that $\beta$-estradiol 3 -glucuronide has been found in the mouse brain, ${ }^{18)} \beta$-estradiol could be metabolized by UGTs in the brain, as glucuronide, with its high water solubility, generally does not easily penetrating the blood-brain barrier. However, the kinetics of $\beta$-estradiol 3-glucuronidation in the brain remain to be elucidated.

In terms of the metabolism of $\beta$-estradiol in rats, a previous study reported that $\beta$-estradiol 3 -glucuronidation occurred in recombinant Ugtlal and Ugtla $7^{19)}$ but not in those recombinant Ugt2b1, Ugt2b2, or Ugt2b3. ${ }^{1)}$ It was not observed in the liver microsomes of Gunn rats, ${ }^{20)}$ suggesting that, similar to humans, $\beta$-estradiol 3 -glucuronidation is catalyzed mainly by
Ugtla isoforms. The purpose of this study was to characterize the $\beta$-estradiol 3-glucuronidation reaction in the rat brain. We conducted kinetic, inhibition, and induction studies of this reaction in the rat brain.

\section{MATERIALS AND METHODS}

Materials Acetaminophen (APAP) was purchased from Nacalai Tesque (Kyoto, Japan). Alamethicin, APAP $\beta$-Dglucuronide, $\beta$-estradiol, $\beta$-estradiol 3 -( $\beta$-D-glucuronide) sodium salt, serotonin hydrochloride, and uridine 5 '-diphosphoglucuronic acid trisodium salt were obtained from SigmaAldrich (St. Louis, MO, U.S.A.). Serotonin $\beta$-D-glucuronide and serotonin- $d_{4} \beta$-D-glucuronide were purchased from Toronto Research Chemicals (Toronto, Canada). Carbamazepine (CBZ), $\beta$-naphthoflavone (BNF), and phenobarbital (PB) were obtained from Wako Pure Chemical Industries, Ltd. (Osaka, Japan). All other chemicals and solvents were of the highest commercial grade available.

Preparation of Brain and Liver Microsomes The present study was approved by the Institution Animal Care and Use Committee of Meijo University. Brains and livers were removed from eight-week-old male Sprague-Dawley rats (Japan SLC, Hamamatsu, Japan). The cerebellum, frontal cortex, parietal cortex, piriform cortex, hippocampus, medulla oblongata, striatum, and thalamus were isolated from the brain. Pooled rat microsomes from brain regions $(n=8)$ and livers $(n=3)$ were prepared as described previously. ${ }^{21)}$

$\beta$-Estradiol 3-Glucuronidation in Rat Brain Regions $\beta$-Estradiol 3-glucuronide levels were determined using a method described previously ${ }^{22}$ with slight modifications. The 
incubation mixture contained $50 \mathrm{~mm}$ Tris (hydroxymethyl) aminomethane- $\mathrm{HCl}$ ( $\mathrm{pH} 7.4), 5 \mathrm{~mm} \mathrm{MgCl}_{2}, 25 \mu \mathrm{g} / \mathrm{mL}$ alamethicin, $3 \mathrm{~mm}$ uridine $5^{\prime}$-diphosphoglucuronic acid, $5 \mu \mathrm{M}$ $\beta$-estradiol, and microsomal proteins (brain: $0.5 \mathrm{mg} / \mathrm{mL}$ or liver: $0.01 \mathrm{mg} / \mathrm{mL}$ ). The reaction mixtures were incubated at $37^{\circ} \mathrm{C}$ at $24 \mathrm{~h}$ (brain) or $10 \mathrm{~min}$ (liver). $\beta$-Estradiol 3 -glucuronide was quantified by LC-MS/MS. The mobile phase was $0.15 \%$ ammonium and methanol $(75: 25, \mathrm{v} / \mathrm{v})$ at a flow rate of $0.2 \mathrm{~mL} / \mathrm{min}$. The detection limit for $\beta$-estradiol 3 -glucuronide was $4.2 \mathrm{fmol}$. The quantification limit in the reaction mixture was $21 \mathrm{~nm}$ with a coefficient of variation of less than $10 \%$.

Kinetic Analysis of $\boldsymbol{\beta}$-Estradiol 3-Glucuronidation in Rat Cerebellum The concentration of $\beta$-estradiol ranged from 0.2 to $200 \mu \mathrm{M}$. Kinetic analysis was performed using the KaleidaGraph computer program (Synergy Software, Reading, PA, U.S.A.). The following equation was applied for Hill kinetic models: $V=V_{\max } \times S^{n} /\left(S_{50}{ }^{n}+S^{n}\right)$, where $V$ is the velocity of the reaction, $V_{\max }$ is the maximum velocity, $S$ is the substrate concentration, $S_{50}$ is the substrate concentration at the half- $V_{\max }$, and $n$ is the Hill coefficient. Maximum clearance $\left(C L_{\max }\right)$ was calculated as $V_{\max } \times(n-1) /\left[S_{50} \times n(n-1)^{1 / n}\right]$ for the Hill kinetic.

Inhibition Study for $\beta$-Estradiol 3-Glucuronidation in Rat Cerebellum and Liver The inhibition study was conducted at $5 \mu \mathrm{M} \beta$-estradiol. Bilirubin $(5-50 \mu \mathrm{M})$, serotonin $(1-10 \mathrm{~mm})$, and APAP $(1-10 \mathrm{~mm})$ were glucuronidated mainly by Ugtla1, ${ }^{23)} \mathrm{Ugtla},{ }^{21)}$ and Ugtla6 and Ugtla7, ${ }^{24)}$ respectively, which were used as the Ugt inhibitors. $\beta$-Estradiol 3 -glucuronidation was analyzed in the presence of each Ugt inhibitor.

Induction Study of $\boldsymbol{\beta}$-Estradiol 3-Glucuronidation in Rat Brain Regions and Liver Eight-week-old male SpragueDawley rats were treated intraperitoneally once daily for $7 \mathrm{~d}$ with $80 \mathrm{mg} / \mathrm{kg} \mathrm{BNF}, 100 \mathrm{mg} / \mathrm{kg} \mathrm{CBZ}$, or $80 \mathrm{mg} / \mathrm{kg}$ PB. For controls, rats were treated with corn oil (control for BNF and $\mathrm{CBZ}$ ) or saline (control for PB). $\beta$-Estradiol 3-glucuronidation was measured using microsomes from eight brain regions and livers, as mentioned above. For correlation analysis, serotonin glucuronidation and APAP glucuronidation were also examined. Serotonin glucuronidation was determined by a previous method $^{21)}$ with slight modification. APAP glucuronidation was performed according to a method described previously. ${ }^{25}$ )

Statistical Analysis Statistical analysis of the experimental data was performed using Student's paired $t$-test with the KaleidaGraph computer system.

\section{RESULTS AND DISCUSSION}

$\beta$-Estradiol 3-glucuronidation was detected in all eight brain regions (Fig. 1). There were, however, regional differences in $\beta$-estradiol 3 -glucuronidation. The highest activity among the eight brain regions was observed in the hippocampus $(0.99 \mathrm{fmol} / \mathrm{min} / \mathrm{mg}$ protein). The $\beta$-estradiol level is known to be associated with hippocampus-dependent memory. ${ }^{26)} \mathrm{A}$ $\beta$-estradiol-generating enzyme, aromatase, is expressed at high levels in the hippocampus CA1-CA3 regions. ${ }^{27)}$ Because UGT is an enzyme involved in the degradation of $\beta$-estradiol, high $\beta$-estradiol glucuronidation activity in the hippocampus would serve to maintain $\beta$-estradiol levels in the hippocampus. $\beta$-Estradiol 3-glucuronidation in the cerebellum was fitted to the Hill equation (Fig. 2). The $S_{50}, V_{\max }$, Hill coefficient, and $C L_{\max }$ were $8.0 \mu \mathrm{M}, 1.30 \mathrm{fmol} / \mathrm{min} / \mathrm{mg}$ protein, 1.1 , and

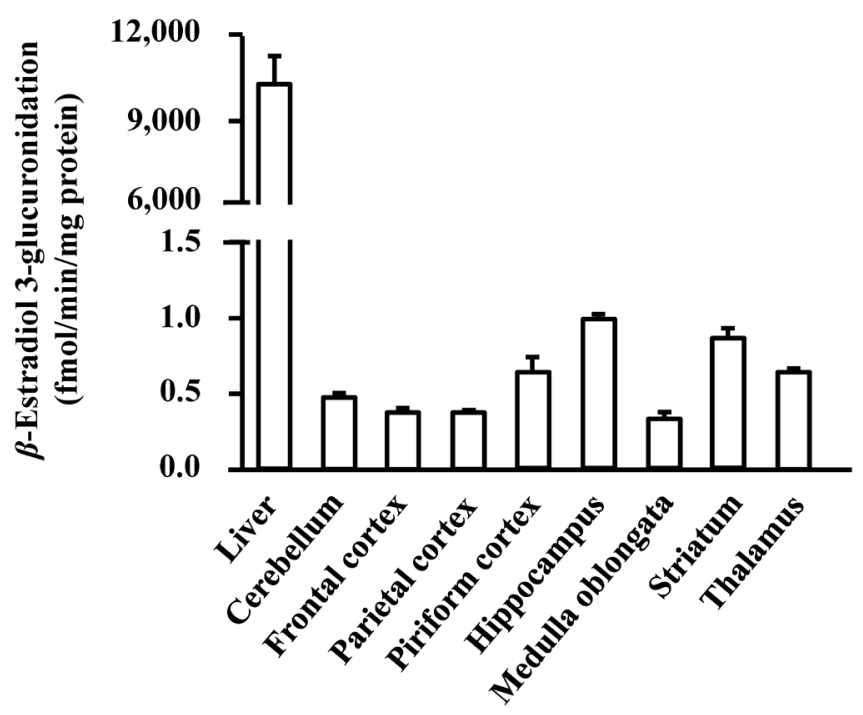

Fig. 1. $\quad \beta$-Estradiol 3-Glucuronidation in Regions of the Rat Brain and Liver

The concentration of $\beta$-estradiol was $5 \mu \mathrm{M}$. Each column represents the mean \pm S.D. of three independent determinations.

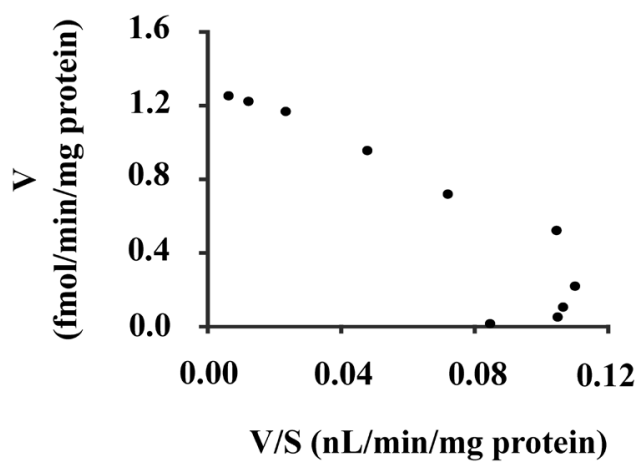

Fig. 2. Eadie-Hofstee Plot for $\beta$-Estradiol 3-Glucuronidation in the Rat Cerebellum

The $\beta$-estradiol concentrations ranged from 0.2 to $200 \mu \mathrm{M}$. The points represent the mean of three independent determinations.

$0.16 \mathrm{~nL} / \mathrm{min} / \mathrm{mg}$ protein, respectively. In some previous studies, $\beta$-estradiol 3 -glucuronidation in the liver was also fitted to the Hill equation with an $S_{50}$ of $16-33 \mu \mathrm{M}$ and a Hill coefficient of $1.8-2.2 .^{28-30}$ ) This suggests that the Ugt isoforms catalyzing $\beta$-estradiol 3 -glucuronidation in the brain may be different from those in the liver.

A previous study using recombinant rat Ugtla isoforms reported that Ugtla1 and Ugtla7 (but not Ugtla2 or Ugtla3) were involved in $\beta$-estradiol 3-glucuronidation. ${ }^{19}$ ) 1 -Naphthol glucuronidation, which is catalyzed mainly by Ugtla6, was inhibited by $\beta$-estradiol in rat ovarian cells. ${ }^{31)}$

For elucidation of the Ugtla isoforms responsible for $\beta$-estradiol 3-glucuronidation in the rat brain, the inhibition of this glucuronidation by typical Ugtla inhibitors was determined (Fig. 3). $\beta$-Estradiol 3-glucuronidation in the cerebellum was reduced to $73.6 \%$ in the presence of bilirubin at $50 \mu \mathrm{M}$. In contrast, in the liver, $\beta$-estradiol 3 -glucuronidation was reduced to $20.5 \%$ by bilirubin at $5 \mu \mathrm{m}$. The inhibitory potency of the Ugtlal inhibitor bilirubin was much weaker in the cerebellum than in the liver. Although Ugtla1, which is expressed at the highest mRNA levels among hepatic Ugtla isoforms, ${ }^{32)}$ accounts mainly for $\beta$-estradiol 3 -glucuronidation 
A

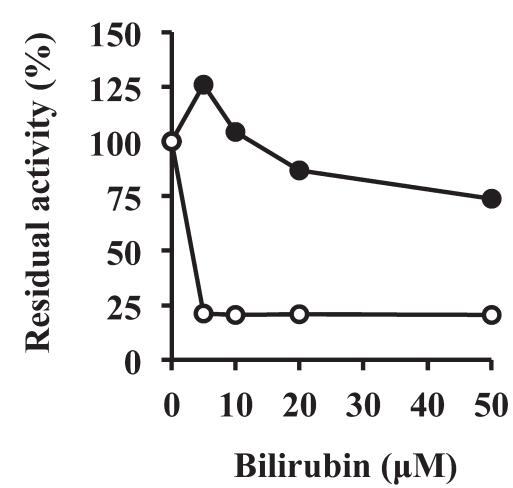

B

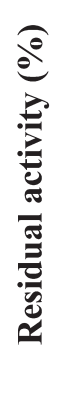

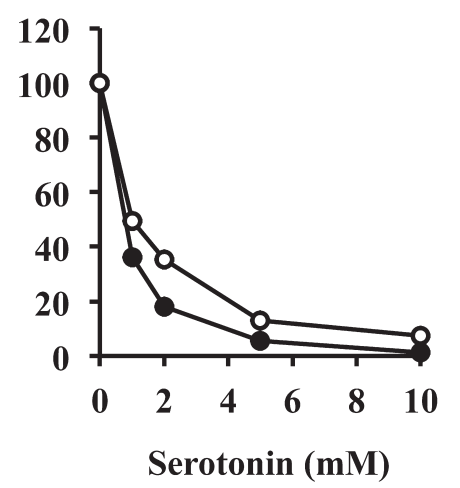

C

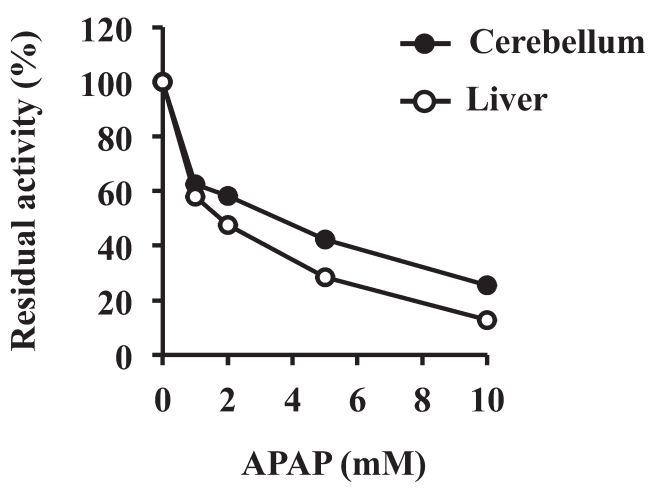

Fig. 3. Inhibitory Effects of Bilirubin (A), Serotonin (B), and APAP (C) on $\beta$-Estradiol 3-Glucuronidation in the Rat Cerebellum and Liver

$\beta$-Estradiol 3-glucuronidation was determined at $5 \mu \mathrm{M} \beta$-estradiol in the presence of UGT inhibitors (bilirubin: $5-50 \mu \mathrm{M}$, serotonin: $1-10 \mathrm{~mm}$, APAP: $1-10 \mathrm{~mm}$ ). Residual activities were calculated by setting the activity in the absence of inhibitors at $100 \%$. Each data point represents the mean of three independent determinations.

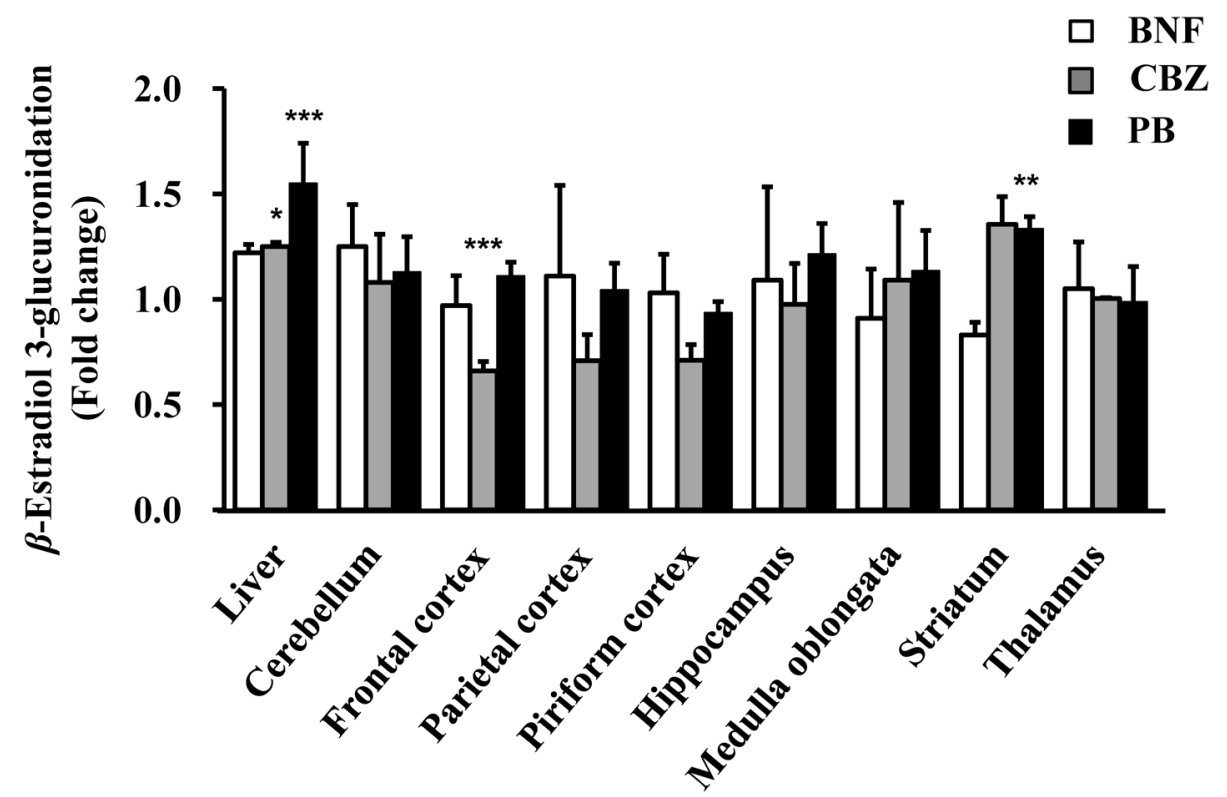

Fig. 4. Changes in $\beta$-Estradiol 3-Glucuronidation Following Treatment with BNF, CBZ, and PB in Regions of the Rat Brain and Liver

The concentration of $\beta$-estradiol was $5 \mu \mathrm{m}$. Each column represents the mean \pm S.D. of three independent determinations. * $p<0.05$, $* * p<0.01, * * * p<0.001$ compared with controls.

in the liver, it may be the minor isoform catalyzing this glucuronidation in the brain. The inhibitory effects of serotonin and APAP on $\beta$-estradiol 3-glucuronidation in the cerebellum were similar to those in the liver. The residual activities in the cerebellum were 1.17 and $25.5 \%$ in the presence of $10 \mathrm{~mm}$ serotonin and $10 \mathrm{~mm}$ APAP, respectively. Constitutive mRNA expression levels of Ugtla6 and Ugtla7 are approximately 16- and 13-fold higher, respectively, than that of Ugtlal in the brain. ${ }^{8)}$ Thus, the results from the inhibition study showed that Ugtla6 and Ugtla7 might be the primary isoforms involved in $\beta$-estradiol 3-glucuronidation in the rat brain.

Ugtla6 and Ugtla7 mRNAs in the rat brain have been reported to be induced by treatment with $\mathrm{BNF}^{25)}$ and $\mathrm{PB}^{33)}$ at the same dosages as those in the present study. If $\beta$-estradiol 3 -glucuronidation is catalyzed mainly by Ugtla6 and Ugtla7, this glucuronidation will be increased by the Ugt inducers in vivo. The present study used BNF, CBZ, and PB as the Ugt inducers, stimulating the nuclear translocation of aryl hydrocar- bon receptor, pregnane $\mathrm{X}$ receptor, and constitutive androstane receptor, respectively. ${ }^{34)}$ In the eight brain regions (Fig. 4), $\mathrm{BNF}, \mathrm{CBZ}$, and $\mathrm{PB}$ did not increase $\beta$-estradiol 3-glucuronidation, except for a 1.3 -fold increase in the striatum with PB. UGT1A is responsible for the conjugation of neurotransmitters such as serotonin ${ }^{2)}$ and dopamine. ${ }^{3)}$ The levels of some Ugtla isoforms that catalyze $\beta$-estradiol 3-glucuronidation were elevated by PB in the striatum, where serotonergic and dopaminergic nerve terminals exist; therefore, the concentrations of these neurotransmitters may change locally. However, $\beta$-estradiol 3-glucuronidation was elevated 1.3- and 1.6-fold in the liver following $\mathrm{CBZ}$ and $\mathrm{PB}$ administration, respectively. $\beta$-Estradiol 3-glucuronidation was unchanged by treatment with BNF. Since Ugtla1 is a target gene of pregnane X receptor and constitutive androstane receptor, ${ }^{35)}$ a statistically significant increase in $\beta$-estradiol 3-glucuronidation in the liver presumably resulted from Ugtlal induction following CBZ and PB administration (Fig. 4). Ugtla6 mRNA was increased 
2.1- and 2.3-fold following BNF treatment in the cerebellum and hippocampus, respectively. ${ }^{25}$ ) Following $\mathrm{PB}$ treatment, Ugtla6 mRNA was induced 3.0- and 2.9-fold in the striatum and thalamus, respectively. ${ }^{33)}$ These results are inconsistent with the hypothesis mentioned above that Ugtla6 and Ugtla7 are involved in this glucuronidation. In addition, $\beta$-estradiol 3 -glucuronidation was not correlated with serotonin $(r=-0.18)$ or APAP $(r=0.01)$ glucuronidation among the eight brain regions. The Ugt isoforms that catalyze $\beta$-estradiol 3 -glucuronidation in the brain are therefore characterized as follows: 1) isoforms that do not mainly catalyze serotonin and APAP glucuronidation, 2) isoforms that are strongly inhibited by serotonin and APAP. It has been reported that Ugtla8 exhibits slight activity for $\beta$-estradiol 3-glucuronidation in rats ${ }^{36)}$ and that Ugtla8 mRNA is expressed in rat brains. $\left.{ }^{8}\right)$ We speculate that not only Ugtla6 and Ugtla7 but also Ugtla1 and Ugtla8 would be involved in $\beta$-estradiol 3 -glucuronidation in the rat brain, but further studies are needed to identify the isoforms that catalyze $\beta$-estradiol 3-glucuronidation.

In conclusion, we clarified that the kinetics of $\beta$-estradiol 3 -glucuronidation in the rat brain could be fitted to the Hill equation with a different profile from that in the liver. Further studies are needed to identify the isoform involved in $\beta$-estradiol 3 -glucuronidation in the rat brain. $\beta$-Estradiol plays an important role in neuroprotection against oxidative stress in the central nervous system; therefore, the elucidation of glucuronidation in the brain may lead to a better understanding of the modulation of $\beta$-estradiol concentration in the brain.

Acknowledgments This work was supported in part by the Japan Society for the Promotion of Science (JSPS) KAKENHI Grant Nos. 25460200 and 16K08385.

Conflict of Interest The authors declare no conflict of interest.

\section{REFERENCES}

1) Itäaho K, Mackenzie PI, Ikushiro S, Miners JO, Finel M. The configuration of the 17-hydroxy group variably influences the glucuronidation of $\beta$-estradiol and epiestradiol by human UDP-glucuronosyltransferases. Drug Metab. Dispos., 36, 2307-2315 (2008).

2) Krishnaswamy S, Hao Q, Von Moltke LL, Greenblatt DJ, Court MH. Evaluation of 5-hydroxytryptophol and other endogenous serotonin (5-hydroxytryptamine) analogs as substrates for UDPglucuronosyltransferase 1A6. Drug Metab. Dispos., 32, 862-869 (2004).

3) Itäaho $\mathrm{K}$, Court MH, Uutela $\mathrm{P}$, Kostiainen R, Radominska-Pandya A, Finel M. Dopamine is a low-affinity and high-specificity substrate for the human UDP-glucuronosyltransferase 1A10. Drug Metab. Dispos., 37, 768-775 (2009).

4) Nakamura A, Nakajima M, Yamanaka H, Fujiwara R, Yokoi T. Expression of UGT1A and UGT2B mRNA in human normal tissues and various cell lines. Drug Metab. Dispos., 36, 1461-1464 (2008).

5) Strassburg CP, Kneip S, Topp J, Obermayer-Straub P, Barut A, Tukey RH, Manns MP. Polymorphic gene regulation and interindividual variation of UDP-glucuronosyltransferase activity in human small intestine. J. Biol. Chem., 275, 36164-36171 (2000).

6) Margaillan G, Rouleau M, Fallon JK, Caron P, Villeneuve L, Turcotte V, Smith PC, Joy MS, Guillemette C. Quantitative profiling of human renal UDP-glucuronosyltransferases and glucuronidation activity: a comparison of normal and tumoral kidney tissues. Drug
Metab. Dispos., 43, 611-619 (2015).

7) King CD, Rios GR, Assouline JA, Tephly TR. Expression of UDPglucuronosyltransferases (UGTs) 2B7 and 1A6 in the human brain and identification of 5-hydroxytryptamine as a substrate. Arch. Biochem. Biophys., 365, 156-162 (1999).

8) Sakakibara Y, Katoh M, Imai K, Kondo Y, Asai Y, Ikushiro S, Nadai M. Expression of UGT1A subfamily in rat brain. Biopharm. Drug Dispos., 37, 314-319 (2016).

9) Suleman FG, Abid A, Gradinaru D, Daval JL, Magdalou J, Minn A. Identification of the uridine diphosphate glucuronosyltransferase isoform UGT1A6 in rat brain and in primary cultures of neurons and astrocytes. Arch. Biochem. Biophys., 358, 63-67 (1998).

10) Gradinaru D, Minn AL, Artur Y, Minn A, Heydel JM. Effect of oxidative stress on UDP-glucuronosyltransferases in rat astrocytes. Toxicol. Lett., 213, 316-324 (2012).

11) Togna AR, Antonilli L, Dovizio M, Salemme A, De Carolis L, Togna GI, Patrignani P, Nencini P. In vitro morphine metabolism by rat microglia. Neuropharmacology, 75, 391-398 (2013).

12) Bidlingmaier F, Strom TM, Dörr HG, Eisenmenger W, Knorr D. Estrone and estradiol concentrations in human ovaries, testes, and adrenals during the first two years of life. J. Clin. Endocrinol. Metab., 65, 862-867 (1987).

13) Li J, Oberly PJ, Poloyac SM, Gibbs RB. A microsomal based method to detect aromatase activity in different brain regions of the rat using ultra performance liquid chromatography-mass spectrometry. J. Steroid Biochem. Mol. Biol., 163, 113-120 (2016).

14) Nuñez J, Yang Z, Jiang Y, Grandys T, Mark I, Levison SW. $17 \beta$-Estradiol protects the neonatal brain from hypoxia-ischemia. Exp. Neurol., 208, 269-276 (2007).

15) Napolitano M, Costa L, Piacentini R, Grassi C, Lanzone A, Gulino A. 17 $\beta$-Estradiol protects cerebellar granule cells against $\beta$-amyloidinduced toxicity via the apoptotic mitochondrial pathway. Neurosci. Lett., 561, 134-139 (2014).

16) Zhao Y, Boyd JM, Sawyer MB, Li XF. Liquid chromatography tandem mass spectrometry determination of free and conjugated estrogens in breast cancer patients before and after exemestane treatment. Anal. Chim. Acta, 806, 172-179 (2014).

17) Sneitz N, Vahermo M, Mosorin J, Laakkonen L, Poirier D, Finel M. Regiospecificity and stereospecificity of human UDP-glucuronosyltransferases in the glucuronidation of estriol, 16-epiestriol, 17-epiestriol, and 13-epiestradiol. Drug Metab. Dispos., 41, 582-591 (2013).

18) Kallonen SE, Tammimäki A, Piepponen P, Raattamaa H, Ketola RA, Kostiainen R. Discovery of neurosteroid glucuronides in mouse brain. Anal. Chim. Acta, 651, 69-74 (2009).

19) Yu C, Ritter JK, Krieg RJ, Rege B, Karnes TH, Sarkar MA. Effect of chronic renal insufficiency on hepatic and renal udp-glucuronyltransferases in rats. Drug Metab. Dispos., 34, 621-627 (2006).

20) Montenegro-Miranda PS, Sneitz N, de Waart DR, Ten Bloemendaal L, Duijst S, de Knegt RJ, Beuers U, Finel M, Bosma PJ. Ezetimibe: A biomarker for efficacy of liver directed UGT1A1 gene therapy for inherited hyperbilirubinemia. Biochim. Biophys. Acta, 1822, 1223-1229 (2012).

21) Sakakibara $Y$, Katoh M, Kawayanagi $T$, Nadai M. Species and tissue differences in serotonin glucuronidation. Xenobiotica, 46, 605-611 (2016).

22) Jäntti SE, Tammimäki A, Raattamaa H, Piepponen P, Kostiainen R, Ketola RA. Determination of steroids and their intact glucuronide conjugates in mouse brain by capillary liquid chromatographytandem mass spectrometry. Anal. Chem., 82, 3168-3175 (2010).

23) Montenegro-Miranda PS, Pañeda A, ten Bloemendaal L, Duijst S, de Waart DR, Gonzalez-Aseguinolaza G, Bosma PJ. Adeno-associated viral vector serotype 5 poorly transduces liver in rat models. PLOS ONE, 8, e82597 (2013).

24) Kessler FK, Kessler MR, Auyeung DJ, Ritter JK. Glucuronidation of acetaminophen catalyzed by multiple rat phenol UDP-glucuronosyltransferases. Drug Metab. Dispos., 30, 324-330 (2002). 
25) Sakakibara $Y$, Katoh M, Kondo Y, Nadai M. Effects of $\beta$-naphthoflavone on Ugt1a6 and Ugtla7 expression in rat brain. Biol. Pharm. Bull., 39, 78-83 (2016).

26) Frick KM. Molecular mechanisms underlying the memory-enhancing effects of estradiol. Horm. Behav., 74, 4-18 (2015).

27) Zhang QG, Wang R, Tang H, Dong Y, Chan A, Sareddy GR, Vadlamudi RK, Brann DW. Brain-derived estrogen exerts antiinflammatory and neuroprotective actions in the rat hippocampus. Mol. Cell. Endocrinol., 389, 84-91 (2014).

28) Shiratani H, Katoh M, Nakajima M, Yokoi T. Species differences in UDP-glucuronosyltransferase activities in mice and rats. Drug Metab. Dispos., 36, 1745-1752 (2008).

29) Alkharfy KM, Frye RF. Sensitive liquid chromatographic method using fluorescence detection for the determination of estradiol 3and 17-glucuronides in rat and human liver microsomal incubations: formation kinetics. J. Chromatogr. B Analyt. Technol. Biomed. Life Sci., 774, 33-38 (2002).

30) Mano Y, Usui T, Kamimura H. Species differences in inhibition potential of nonsteroidal anti-inflammatory drugs against estradiol 3beta-glucuronidation between rats, dogs, and humans. J. Pharm. Sci., 97, 2805-2810 (2008).
31) Boström M, Becedas L, DePierre JW. Conjugation of 1-naphthol in primary cell cultures of rat ovarian cells. Chem. Biol. Interact., 124, 103-118 (2000).

32) Shelby MK, Cherrington NJ, Vansell NR, Klaassen CD. Tissue mRNA expression of the rat UDP-glucuronosyltransferase gene family. Drug Metab. Dispos., 31, 326-333 (2003).

33) Sakakibara Y, Katoh M, Kondo Y, Nadai M. Effects of phenobarbital on expression of UDP-glucuronosyltransferase 1a6 and 1a7 in rat brain. Drug Metab. Dispos., 44, 370-377 (2016).

34) Bock KW. From differential induction of UDP-glucuronosyltransferases in rat liver to characterization of responsible ligand-activated transcription factors, and their multilevel crosstalk in humans. Biochem. Pharmacol., 82, 9-16 (2011).

35) Shelby MK, Klaassen CD. Induction of rat UDP-glucuronosyltransferases in liver and duodenum by microsomal enzyme inducers that activate various transcriptional pathways. Drug Metab. Dispos., 34, $1772-1778$ (2006)

36) Webb LJ, Miles KK, Auyeung DJ, Kessler FK, Ritter JK. Analysis of substrate specificities and tissue expression of rat UDP-glucuronosyltransferases UGT1A7 and UGT1A8. Drug Metab. Dispos., 33, 77-82 (2005). 